Medicine Berlin, Department of Rheumatology and Clinical Immunology, Berlin, Germany

Background: In patients with JIA, growth impairment and variance in body composition are well-known long-term complications that may be associated with prolonged drug therapy (e.g. glucocorticoids) as well as impaired physical and psychosocial well-being. An increased accumulation of body fat represents a significant risk factor for metabolic abnormalities and a modifiable variable for a number of comorbidities. Recently, evidence has emerged in favour of the potential negative influence of overweight on the course of the disease and treatment response [1].

Objectives: The study aimed a) to estimate the prevalence of underweight, overweight and obesity in children and adolescents with JIA compared to the general population, and b) to investigate correlates of patients' weight status.

Methods: A cross-sectional analysis of physicians' recorded body weights and heights of patients with JIA enrolled in the NPRD in the year 2019 was performed. Underweight (BMI <10th), overweight (BMI >90th) and obesity (BMI $>97$ th) were defined according to age- and sex-specific percentiles used in the German reference system. For comparison with data from the general population [2], sex- and age-matched pairs of 3-17-year-old patients and controls were generated. A multinomial logistic regression analysis was performed to examine the association between weight status and patients' clinical and self-reported outcomes.

Results: In total, data from 6.515 children and adolescents with JIA (age 11.2 \pm 4.1 years, disease duration $4.9 \pm 3.8$ years, $67 \%$ girls, $40 \%$ persistent oligoarthritis) were included. Of these, 3.334 (age $5.9 \pm 2.1$ years, $52.5 \%$ girls) could be considered for matched-pair analysis. Compared with the general population, patients underweight, overweight and obesity rates were $10.6 \%$ (vs. $8.1 \%$ ), $8.8 \%$ (vs. $8.5 \%$ ) and $6.1 \%$ (vs. $5.7 \%$ ), respectively. No significant sex differences were found in either group. Largest difference in prevalence was registered for underweight, specifically in the age group 3-6 years (12.9\% patients vs. $5.9 \%$ controls). Similar to the general population, higher rates of overweight were observed in adolescent patients than in affected children (19.1\% age group $11-13$ vs. $8.4 \%$ age group $3-6)$. While the highest underweight prevalence was registered in patients with $R F+$ polyarthritis $(16 \%)$, patients with Enthesitis-related arthritis (22\%), psoriatic arthritis $(21 \%)$ and systemic JIA (20\%) showed the highest overweight rates (including obesity). Younger age $(\mathrm{OR}=0.51,95 \% \mathrm{Cl}=0.31-0.83)$, more frequent physical activity $(\mathrm{OR}=0.92,95 \% \mathrm{Cl}=0.85-0.99)$ and high parental vocational education (OR $=0.39,95 \% \mathrm{Cl}=0.18-0.80$ ) were independently associated with a lower likelihood of being overweight/obese.

Conclusion: The overall prevalence of underweight, overweight and obesity in children and adolescents with JIA is comparable to that found in the general population. Behavioural health promotion, including regular physical activity, as part of the treatment strategy in JIA should preventively already begin at preschool age and necessarily be made accessible to patients of all educational levels.

REFERENCES:

[1] Giani T et al. The influence of overweight and obesity on treatment response in juvenile idiopathic arthritis. Front Pharmacol 2019;10:637.

[2] Schienkiewitz A et al. BMI among children and adolescents: prevalences and distribution considering underweight and extreme obesity. Bundesgesundheitsbl 2019;62:1225-1234.

Acknowledgements: The National Paediatric Rheumatological Database has been funded by AbbVie, Chugai, Novartis and GSK.

Disclosure of Interests: Florian Milatz: None declared, Jens Klotsche: None declared, Martina Niewerth: None declared, Jana Hörstermann: None declared, Daniel Windschall: None declared, Frank Weller-Heinemann Speakers bureau: Pfizer, AbbVie, SOBI, Roche and Novartis., Frank Dressler: None declared, Rainer Berendes: None declared, Johannes-Peter Haas: None declared, Gerd Horneff: None declared, Kirsten Minden Speakers bureau: Pfizer, AbbVie, Consultant of: Novartis

DOI: 10.1136/annrheumdis-2021-eular.2058

\section{POS1310 1 CANAKINUMAB IS A RESCUE TREATMENT FOR MACROPHAGE ACTIVATION SYNDROME IN PATIENTS WITH SYSTEMIC ONSET JUVENILE IDIOPATHIC ARTHRITIS: SINGLE CENTER EXPERIENCE}

M. Kostik ${ }^{1}$, E. Isupova ${ }^{1}$, I. Chikova ${ }^{1}$, T. Likhacheva ${ }^{1}$, V. Masalova ${ }^{1}$ L. Snegireva ${ }^{1}$, M. Dubko ${ }^{1}$, E. Gaidar ${ }^{1}$, M. Kaneva $^{1}$, T. Kornishina ${ }^{1}$ O. Kalashnikova ${ }^{1}$, V. Chasnyk ${ }^{1}{ }^{1}$ Saint Petersburg State Pediatric Medical University, Hospital Pediatry, Saint-Petersburg, Russian Federation

Background: Macrophage activation syndrome (MAS) is a severe life-threatening complication of the systemic-onset juvenile idiopathic arthritis (soJIA). The treatment options included high-dose of the corticosteroids (CS), cyclosporine A (CsA), intravenous immunoglobulin (IVIG) and biologics, predominantly IL-1 antagonist - anakinra. In Russia anakinra has not approved yet, so canakinumab (CAN) is a single anti-IL-1 option, available in Russia.

Objectives: To evaluate the safety and efficacy of canakinumab in patients with severe MAS in SoJIA, who failed the previous treatment.

Methods: In the retrospective case series study were included 9 soJIA patients (4 boys and 5 girls) with severe MAS, resistant to combination of high-dose CS IVIG and CsA.

Results: All patients had a MAS during the onset of JIA. The main clin ical features of disease onset included: fever $9(100 \%)$, active arthritis 5 $(56 \%)$, pleuritis $7(78 \%)$, pericarditis - $5(56 \%)$, peritonitis $2(22 \%)$, rash $6(67 \%)$, hepatomegaly $9(100 \%)$, splenomegaly $9(100 \%)$, lymphadenopathy $7(78 \%)$, bleeding $4(44 \%)$, CNS involvement $-3(33 \%)$. Initial treatment included high doses CS $8(89 \%)$, oral CS $9(100 \%)$, methotrexate $5(56 \%)$, tocilizumab $4(44 \%)$, and canakinumab $5(56 \%)$, CsA $4(44 \%)$, IVIG $6(67 \%)$. TCZ was discontinued due to infusion reaction $(n=2)$, TCZ inefficacy $(n=3)$ and presence of MAS in all patients $(n=5)$. In children whom TCZ was switched on CAN we used the standard dose of CAN $4 \mathrm{mg} / \mathrm{kg}$, but if MAS occurred on the CAN we temporally increased the doses since 8 to $25 \mathrm{mg} / \mathrm{kg}$ (300 mg). In all cases MAS episodes were successfully resolved during CAN treatment. In 5 (56\%) MAS had repeated course during the CAN which lead to temporally increasing the doses of CAN (pt3, pt5, pt8, pt 9) or required to increase immunosupression with abatacept or tofacitinib. Three patients with repeated MAS developed interstitial lung disease (ILD). Two patients who successfully resolved MAS after CAN had relapses of arthritis and switched CAN to TCZ.

\begin{tabular}{|c|c|c|c|c|c|c|c|c|}
\hline ID & Sex & $\begin{array}{l}\text { JIA } \\
\text { onset, } \\
y\end{array}$ & Repeated MAS & $\begin{array}{l}\text { Initial } \\
\text { bio- } \\
\text { logic }\end{array}$ & $\begin{array}{l}\text { MAS } \\
\text { on } \\
\text { CAN }\end{array}$ & $\begin{array}{l}\text { Experience } \\
\text { of increased } \\
\text { CAN doses }\end{array}$ & Outcomes & $\begin{array}{l}\text { Current } \\
\text { treatment }\end{array}$ \\
\hline 1 & $\mathrm{~F}$ & 7.7 & $\mathrm{~N}$ & TCZ & $\mathrm{N}$ & $\mathrm{N}$ & Remission & CAN \\
\hline 2 & $\mathrm{~F}$ & 11.5 & $\mathrm{~N}$ & CAN & $\mathrm{N}$ & $\mathrm{N}$ & soJIA flare, ILD & TCZ \\
\hline 3 & $\mathrm{~F}$ & 7.9 & $Y$ & CAN & $Y$ & $Y$ & Remission & CAN \\
\hline 4 & $\mathrm{~F}$ & 3.4 & $\mathrm{~N}$ & TCZ & $\mathrm{N}$ & $\mathrm{Y}$ & Remission, ILD & CAN, CS, MMF \\
\hline 5 & $M$ & 0.8 & $Y$ & $\mathrm{TCZ}$ & $\mathrm{Y}$ & $Y$ & Remission, ILD & $\begin{array}{l}\text { CAN, abata- } \\
\text { cept, CsA, } \\
\text { CS }\end{array}$ \\
\hline 6 & $M$ & 14.2 & $Y$ & CAN & $\mathrm{N}$ & $\mathrm{N}$ & Remission & $\mathrm{TCZ}$ \\
\hline 7 & M & 1.1 & $\mathrm{Y}$ & CAN & $\mathrm{N}$ & $\mathrm{N}$ & Remission & $\mathrm{N}$ \\
\hline 8 & $M$ & 1.3 & $\mathrm{~N}$ & CAN & $\mathrm{Y}$ & $\mathrm{Y}$ & Remission & $\begin{array}{l}\text { CAN every } 12 \\
\text { months }\end{array}$ \\
\hline 9 & $\mathrm{~F}$ & 9.1 & $\mathrm{~N}$ & TCZ & $\mathrm{Y}$ & $\mathrm{Y}$ & $\begin{array}{l}\text { Minimal disease } \\
\text { activity }\end{array}$ & CAN, tofacitinib \\
\hline
\end{tabular}

Footnotes: CAN - canakinumab, CS - corticosteroids, CsA - cyclosporine A, ID - identification, ILD - interstitial lung disease, $\mathrm{F}$ - females, $\mathrm{M}$ - males, $\mathrm{N}$ - no, TCZ - tocilizumab, $\mathrm{Y}$ - yes.

Conclusion: Canakinumab is an effective rescue treatment either soJIA either MAS. In patients with MAS developed on CAN required the temporal increasing of the doses.

Funding statement: This work was supported by the Russian Foundation for Basic Research (grant № 18-515-57001)

Disclosure of Interests: None declared

DOI: 10.1136/annrheumdis-2021-eular.2141

\section{POS1311 SCLERODERMA PATTERN IN NAILFOLD CAPILLARIES OF (CHILDHOOD-ONSET) SYSTEMIC LUPUS ERYTHEMATOSUS: LESSONS FROM LONGITUDINAL FOLLOW-UP}

D. Schonenberg-Meinema ${ }^{1}$, S. Bergkamp ${ }^{1}$, A. Nassar-Sheikh Rashid ${ }^{1}$, M. Gruppen ${ }^{1}$, A. E. Hak², P. C. E. Hissink Muller ${ }^{3}$, M. Middelkamp ${ }^{4}$, M. Van Onna $^{2}$, T. Kuijpers ${ }^{5}$, V. Smith ${ }^{6}$, J. M. Van den Berg ${ }^{1}$ on behalf of EULAR study group on Microcirculation in Rheumatic Diseases. ${ }^{1}$ Amsterdam UMC, locatie AMC, Pediatric Immunology, Rheumatology and Infectious Diseases, Amsterdam, Netherlands; ${ }^{2}$ Amsterdam UMC, locatie AMC, Amsterdam Rheumatology and Immunology Centre, Department of Rheumatology and Clinical Immunology, Amsterdam, Netherlands; ${ }^{3}$ Leiden University Medical Center (LUMC), Department of Pediatric Rheumatology, Leiden, Netherlands; ${ }^{4}$ Amsterdam UMC, locatie AMC, Department of Dermatology, Amsterdam, Netherlands: ${ }^{5}$ Amsterdam UMC, locatie AMC, Department of Pediatric Immunology, Rheumatology and Infectious diseases, Amsterdam, 